\title{
Pengaruh Komposisi Kulit Buah Kakao, Ampas Tebu, dan Perekat terhadap Sifat Fisis dan Mekanis Papan Partikel dari Campuran Limbah Kulit Buah Kakao dan Ampas Tebu
}

\author{
Yeni Fathatun Najihah ${ }^{1, *}$, Dwi Puryanti ${ }^{1}$, Yuli Yetri ${ }^{2, * *}$ \\ ${ }^{1}$ Jurusan Fisika FMIPA Universitas Andalas, Padang, Indonesia \\ ${ }^{2}$ Jurusan Teknik Mesin, Politeknik Negeri Padang, Padang, Indonesia \\ *yenifathatun@gmail.com \\ **yuliyetriyetri@gmail.com
}

\begin{abstract}
ABSTRAK
Penelitian ini bertujuan untuk mengetahui perlakuan bahan terbaik terhadap sifat fisis dan mekanis papan partikel. Dalam penelitian ini digunakan dua variasi perlakuan bahan, yaitu perbandingan komposisi bahan dan jumlah perekat. Variasi komposisi bahan yang digunakan antara kulit buah kakao dan ampas tebu adalah 100:0\%, 75:25\%, 50:50\%. Kadar perekat isosianat yang digunakan adalah 12\%, 14\%, dan $16 \%$. Ukuran panjang serat ampas tebu yang digunakan adalah $3 \mathrm{~cm}$. Parameter yang diukur adalah kadar air, kerapatan, daya serap air, keteguhan patah, kuat tekan sejajar permukaan dan kekuatan rekat internal. Didapatkan papan partikel terbaik adalah papan partikel dengan perbandingan komposisi bahan 50:50\% dengan kadar perekat $16 \%$. Hasil penelitian menunjukkan bahwa nilai sifat fisis yang dihasilkan memenuhi standar JIS A 5908 (2003), SNI 03-2105-2006, dan FAO (1996). Namun pada pengujian sifat mekanis terdapat beberapa nilai MOR papan partikel yang tidak memenuhi standar. Berdasarkan persentase densitas papan partikel maka papan partikel yang dihasilkan termasuk jenis medium density particle board hingga high density particle board.

Kata kunci: kulit buah kakao, ampas tebu, perekat isosianat, papan partikel
\end{abstract}

\begin{abstract}
This research is to know the best material treatment of physical and mechanical properties of particle board. In this research two variations of material treatment were used, namely the effect of composition ratio of materials and the number of adhesives. The composition variation of the ingredients between cacao peels and bagasse that was used 100: 0\%, 75: 25\%, 50: 50\%. The isocyanate adhesive content used was $12 \%, 14 \%$, and 16\%. The length of the bagasse fiber used is $3 \mathrm{~cm}$. Parameters measured were moisture content, density, water absorption, fracture toughness, parallel compressive strength of the surface and internal stickiness. The best particle board is a particle board with a composition ratio of 50:50\% with $16 \%$ adhesive content. The results showed that the resulting physical properties met JIS A 5908 (2003), SNI 03-2105-2006, and FAO (1996) standards. However, in the mechanical properties test there are some particle board MOR values that do not meet the standards. Based on the percentage of particle board density, the resulting particle board includes the type of medium density particle board up to high density particle board.
\end{abstract}

Keywords: cacao peel, bagasse, isocyanate adhesive, particle board

\section{PENDAHULUAN}

Papan partikel merupakan material pengganti kayu yang terbuat dari serat alami yang mengandung lignoselulosa. Pada umumnya serat alami yang digunakan seperti serbuk gergaji, sekam padi, ampas sagu, ampas tebu atau serat lainnya yang dapat dimanfaatkan dalam pembuatan papan partikel. Ampas tebu dan kulit kakao merupakan limbah yang sangat melimpah di lapangan. Dalam penelitian ini dilakukan pencampuran kedua bahan baku kulit kakao dan ampas tebu. Pencampuran kulit buah kakao dan ampas tebu pada papan partikel dimaksudkan untuk mendapatkan hasil papan partikel terbaik.

Selama ini pemanfaatan tebu masih terbatas pada industri pengolahan gula dengan hanya mengambil airnya, sedangkan ampasnya sekitar 35-40\% dari berat tebu yang digiling hanya dimanfaatkan sebagai bahan bakar industri atau mungkin dibuang sehingga menjadi limbah. Melalui pembuatan papan partikel dari ampas tebu diharapkan terjadi peningkatan nilai tambah dari tanaman tebu dan dapat mengurangi pencemaran lingkungan akibat limbah ampas tebu yang terbuang. Serat ampas tebu tidak dapat larut dalam air, oleh karena itu ampas tebu memenuhi persyaratan untuk diolah menjadi papan buatan (Maiwita dkk, 2014). 
Provinsi Sumatera Barat, ialah wilayah yang sedang menggalakkan program penanaman kakao. Saat ini kakao di daerah ini dimanfaatkan untuk diambil bijinya, dikeringkan dan kemudian dijual. Limbah kulit kakao merupakan inti permasalahan dari penggalakan program ini yaitu kurangnya pemanfaatan limbah kulit kakao yang dibuang selama pemanenan. Kulit atau biasa disebut cangkang buah kakao juga menyimpan lignoselulosa sama seperti ampas tebu. Kandungan ini berguna dalam komposit, yaitu dalam pembuatan papan partikel. Selain itu limbah kulit kakao cukup mudah dijumpai untuk saat ini. Produksi satu ton biji kakao kering menghasilkan sekitar 10 ton kulit buah kakao segar (Figueira dkk., 1993). Sehingga jika dikalkulasikan dalam 32.376 ton kakao akan menghasilkan sebanyak 323.760 ton kulit buah kakao. Artinya akan dihasilkan lignoselulosa dari kulit kakao dalam jumlah besar setiap 1 tahun panen.

Setiap tahun produksi kakao semakin bertambah, otomatis jumlah limbah kulit kakao juga meningkat. Untuk itu diperlukan solusi dalam memanfaatkannya secara masiv. Dengan dimanfaatkannya limbah ini sebagai bahan untuk pembuatan papan partikel, maka akan membantu pemerintah dalam menekan produksi papan dari bahan kayu serta menangani permasalahan limbah yang terbuang sia-sia.

Penelitian mengenai papan partikel telah banyak dilakukan diantaranya oleh Malau (2015) dengan perlakuan variasi kadar perekat phenol formaldehida (PF) mendapatkan perlakuan terbaik yang dihasilkan dari penelitian ini adalah pada kadar perekat PF 16\%. Dan juga dilakukan oleh Marpaung (2015) dengan hasil penelitian menunjukkan bahwa papan partikel terbaik adalah dengan menggunakan kadar perekat $14 \%$, dengan hasil nilai kerapatan $0,76 \mathrm{~g} / \mathrm{cm}^{3}$, nilai kadar air 6,33\%, nilai daya serap air 26,38 \%, nilai MOR 99,31 kg/cm 2 , dan nilai IB sebesar $1,6 \mathrm{~kg} / \mathrm{cm}^{2}$. Berdasarkan penelitian sebelumnya, maka akan dilakukan penelitian tentang pengaruh variasi komposisi bahan, panjang serat dan kadar perekat terhadap sifat fisik dan mekanik papan partikel.

\section{METODE}

Bahan yang digunakan dalam penelitian ini adalah kulit kakao yang didapatkan dari perkebunan rakyat di Kecamatan V Koto Kampung Dalam Kabupaten Padang Pariaman, perekat isosianat, air dan bahan untuk analisis lainnya. Kulit kakao masih dalam kondisi utuh diiris tipis menggunakan pisau lalu dikeringkan selama 7 hari, kemudian digrinding untuk memperkecil ukuran sehingga diperoleh partikel dengan ukuran yang diinginkan. Partikel yang digunakan yaitu partikel yang lolos ayakan 60 mesh. Sedangkan ampas tebu sebagai hasil limbah dari alat press pedagang saat mengeluarkan air dari tebu juga dikumpulkan. Kemudian direndam selama 2 jam untuk menghilangkan zat gula yang masih tersimpan pada ampas tebu. Ampas tebu yang selesai direndam dikering-anginkan. Selanjutnya dibersihkan dan dipotong dengan ukuran panjang $3 \mathrm{~cm}$. Papan partikel yang dibuat berukuran $20 \mathrm{~cm} \times 20 \mathrm{~cm}$ x $1 \mathrm{~cm}$ dengan target kerapatan yang ditetapkan adalah $0,8 \mathrm{~g} / \mathrm{cm}^{3}$. Keperluan bahan total dengan perhitungan: $20 \mathrm{~cm}$ x $20 \mathrm{~cm}$ x $1 \mathrm{~cm}$ x $0,8 \mathrm{~g} / \mathrm{cm}^{3}$, jadi massa untuk satu papan adalah 320 gram. Penelitian ini menggunakan dua variasi perlakuan bahan yaitu variasi komposisi bahan dan kadar perekat. Variasi komposisi bahan antara kulit kakao dan ampas tebu adalah 100:0\%, $75: 25 \%$, dan 50:50\%. Sedangkan untuk variasi kadar perekat yaitu 12\%, 14\%, dan $16 \%$.

Adapun tahapan pembuatan papan partikel adalah bahan ditimbang sesuai dengan yang dibutuhkan, perekat dicampur dengan partikel dengan diaduk, campuran bahan dituangkan ke dalam cetakan yang berukuran $20 \mathrm{~cm}$ x $20 \mathrm{~cm}$ x $1 \mathrm{~cm}$ yang diletakkan di atas plat aluminium, ditutup dengan plat aluminium dan dikempa dingin sampai terbentuk lembaran papan dengan ketebalan kurang lebih $1 \mathrm{~cm}$, lalu dimasukkan ke dalam kempa panas selama 6 menit sesuai perlakuan penelitian, dikondisikan dalam suhu ruang selama lebih kurang 7 hari dan kemudian dilakukan pengujian sifat fisis dan mekanis.

Pengujian sifat fisis dan mekanis papan partikel dilakukan berdasarkan standar JIS A 5908-2003, standar SNI 03-2105-2006, dan standar FAO (1996). Parameter kualitas papan partikel yang diuji untuk sifat fisis adalah kadar air, densitas dan daya serap air. Sedangkan untuk sifat mekanis yang diuji adalah kuat patah (MOR $=$ modulus of rupture), kuat tekan sejajar permukaan (KTSP), dan kuat rekat (IB = internal bonding). 


\section{HASIL DAN DISKUSI}

\subsection{Kadar Air (KA)}

Kadar air merupakan hasil dari selisih berat papan sebelum dan sesudah pengovenan kemudian dibagi dengan berat sesudah pengovenan. Hasil pengujian menunjukkan nilai kadar air $0,05-0,117 \%$. Kadar air tertinggi dihasilkan oleh papan partikel dengan komposisi kulit buah kakao: ampas tebu 100:0 \% dengan kadar perekat $12 \%$. Kadar air terendah diperoleh oleh papan partikel dengan komposisi kulit buah kakao: ampas tebu 50:50 \% dengan kadar perekat $16 \%$. Nilai kadar air papan partikel semakin rendah dengan pertambahan kadar perekat, sesuai dengan yang dilakukan oleh Marpaung (2015) dan juga dilakukan oleh Sulastiningsih dkk. (2006) yang meneliti pengaruh kadar perekat urea formaldehid terhadap sifat papan partikel bambu dengan hasil kadar air papan partikel minimum yaitu 7,01\% dengan kadar perekat tertinggi sebesar $12 \%$. Hasil penelitian ini menunjukkan bahwa besar nilai kadar air tergantung kepada jumlah perekat dalam papan partikel. Selain itu komposisi bahan juga berpengaruh terhadap nilai kadar air, semakin tinggi jumlah serat maka semakin rendah nilai kadar air. Nilai kadar air papan partikel yang dihasilkan telah memenuhi standar JIS A 5908-2003 yang mensyaratkan nilai kadar air 5\%-13\%, dan standar SNI 03-2105-2006 dengan syarat kadar air maksimal $14 \%$.

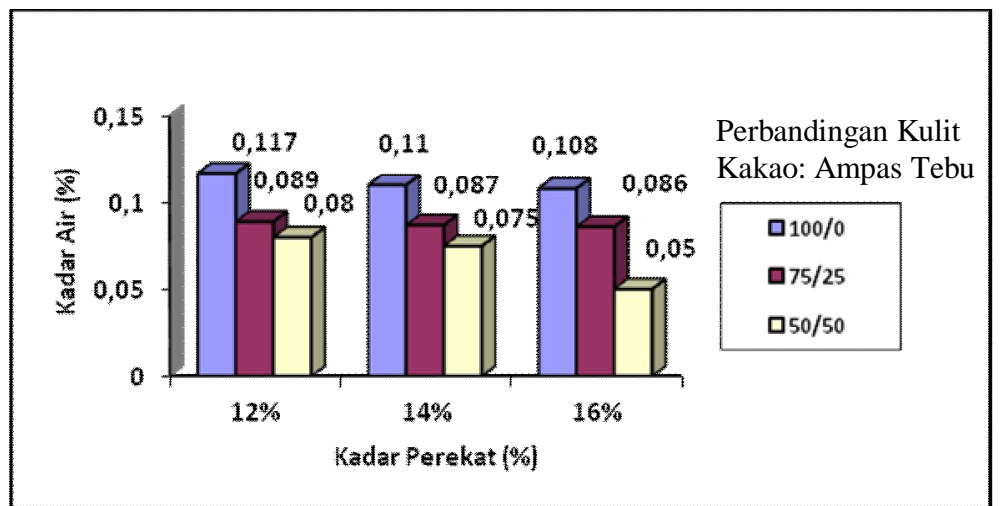

Gambar 1 Pengaruh Komposisi Kulit Buah Kakao, Ampas Tebu, dan Perekat terhadap Kadar Air Papan Partikel

\subsection{Densitas}

Pengujian densitas dilakukan pada kondisi kering udara dan volume kering udara. Nilai densitas suatu papan dalam standar biasanya dinyatakan dalam kisaran tertentu. Gambar 2 memperlihatkan bahwa nilai densitas yang dihasilkan berkisar antara 0,820-0,968 $\mathrm{g} / \mathrm{cm}^{3}$. Semakin tinggi kadar perekat maka semakin tinggi nilai kerapatan papan partikel. Pengaruh kadar perekat terhadap kerapatan diduga karena ikatan kimia yang terjadi pada perekat isosianat (Marpaung, 2015). Dalam penelitian ini, nilai kerapatan tertinggi diperoleh oleh papan partikel dengan kadar perekat tertinggi yaitu $16 \%$. Sesuai dengan penelitian yang telah dilakukan oleh Sulastiningsih dkk. (2006) yang menghasilkan kerapatan papan partikel bambu $0,71 \mathrm{~g} / \mathrm{cm}^{3}$ dengan kadar perekat UF $12 \%$. Kerapatan juga dipengaruhi oleh kadar air yang dimiliki papan partikel. Hal lain yang mempengaruhi kerapatan adalah komposisi bahan, dapat dilihat pada Tabel 3.2 semakin sedikit jumlah serat maka semakin tinggi nilai kerapatan papan partikel. Dari hasil pengujian dapat dilihat bahwa nilai kerapatan, papan partikel yang didapatkan dapat digolongkan menjadi medium density particle board dengan standar $0,4-0,8 \mathrm{~g} / \mathrm{cm}^{3}$ dan high density particle board dengan standar $>0,8 \mathrm{~g} / \mathrm{cm}^{3}$. Nilai kerapatan yang dihasilkan sudah memenuhi standar SNI 03-2105-2006, JIS A 5908 (2003) 0,4-0,9 g/ $\mathrm{cm}^{3}$, serta standar FAO (1996) yaitu $0,42-0,80 \mathrm{~g} / \mathrm{cm}^{3}$. 


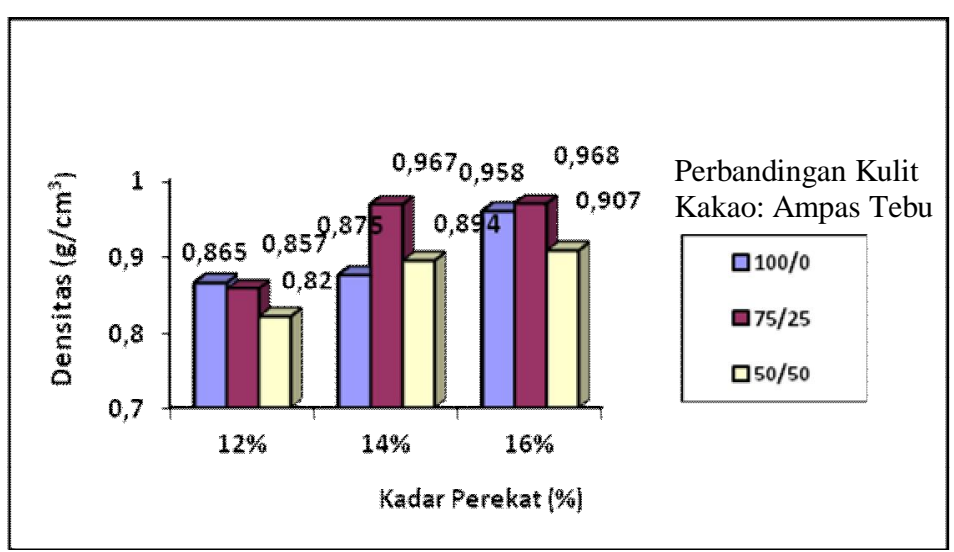

Gambar 2 Pengaruh Komposisi Kulit Buah Kakao, Ampas Tebu, dan Perekat terhadap Densitas Papan Partikel

\subsection{Daya Serap Air (DSA)}

Daya serap air merupakan kemampuan papan untuk menyerap air selama 24 jam. Papan partikel dengan ukuran $5 \times 5 \times 1 \mathrm{~cm}$ ditimbang untuk menentukan massa kering $\left(m_{k}\right)$, kemudian papan direndam dalam air selama 24 jam. Setelah perendaman 24 jam ditimbang kembali massa basah $\left(m_{b}\right)$. Nilai daya serap air yang dihasilkan dari papan partikel berkisar antara 0,283-1,164 \%. Nilai daya serap terendah oleh papan partikel dengan kadar perekat $16 \%$ dengan komposisi kulit bauh kakao: ampas tebu 50:50\% dan nilai daya serap air tertinggi dihasilkan oleh papan dengan kadar perekat $12 \%$ dengan komposisi kulit buah kakao: ampas tebu 100:0 \%. Hal ini menunjukkan bahwa kadar perekat berpengaruh nyata terhadap nilai daya serap air papan partikel, semakin tinggi kadar perekat maka semakin rendah ilai daya serap air. Sesuai dengan penelitian yang dilakukan Sucipto dkk. (2010) yang melakukan penelitian papan partikel dari limbah batang sawit dengan kadar perekat $10 \%$ menghasilkan nilai daya serap air sebesar 9,27\%. Hasil penelitian daya serap air pada Gambar 3 juga memperlihatkan bahwa semakin banyak serat maka semakin rendah kemungkinan papan partikel menyerap air. Dari hasil pengujian rata-rata daya serap air papan tanpa serat ampas tebu yang didapatkan memenuhi standar FAO (1996) yaitu 6-40 \%, sedangkan standar SNI dan JIS tidak mensyaratkan pengujian nilai daya serap air.

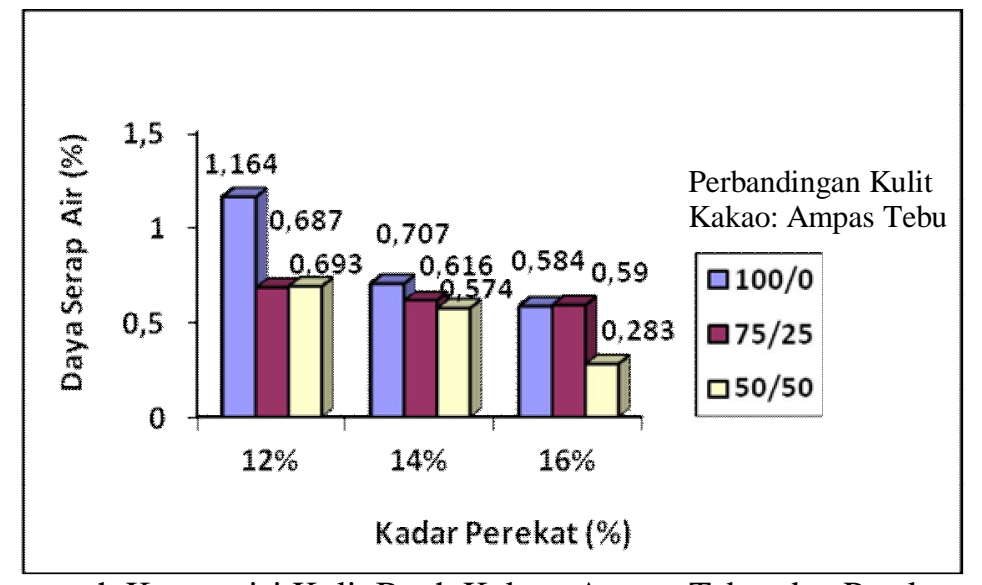

Gambar 3 Pengaruh Komposisi Kulit Buah Kakao, Ampas Tebu, dan Perekat terhadap Daya Serap Air Papan Partikel

\subsection{Kuat Patah (MOR = modulus of rupture $)$}

Keteguhan patah adalah tingkat keteguhan papan partikel dalam menerima beban tegak lurus terhadap permukaan papan (Marpaung dkk., 2015). Dari Gambar 4 dapat dilihat bahwa papan partikel dengan $50 \%$ serat ampas tebu dengan kadar perekat $16 \%$ menghasilkan nilai MOR tertinggi. Sedangkan nilai MOR terendah dihasilkan dari papan dengan komposisi kulit buah kakao: ampas tebu 100:0 \% atau tanpa serat dengan kadar perekat $12 \%$. Hasil pengujian 
nilai MOR yang diperoleh menunjukkan bahwa semakin tinggi kadar perekat dalam papan maka akan mengakibatkan nilai MOR semakin tinggi. Sesuai dengan penelitian yang dilakukan Marpaung (2015) yang menggunakan limbah serbuk gergajian pada penelitiannya, nilai MOR tertinggi dihasilkan oleh papan partikel dengan kadar perekat tertinggi yaitu $14 \%$ menghasilan nilai MOR sebesar $99,31 \mathrm{~kg} / \mathrm{cm}^{2}$. Hasil pengujian nilai MOR pada Gambar 4 menunjukkan bahwa penambahan serat mempengaruhi nilai MOR papan partikel. Semakin banyak serat yang ditambahkan ke dalam papan partikel maka semakin tinggi nilai MOR papan partikel yang dihasilkan. Nilai MOR dengan komposisi kulit buah kakao: ampas tebu 100:0 \%, serta nilai MOR papan partikel dengan komposisi kulit buah kakao: ampas tebu 75:25\% dengan kadar perekat $12 \%$ belum memenuhi standar SNI 03-2105-2006, JIS A 5908 (2003) yang mensyaratkan minimal $82 \mathrm{~kg} / \mathrm{cm}^{2}$ dan FAO 1996 dengan syarat nilai MOR berkisar antara 108$280 \mathrm{~kg} / \mathrm{cm}^{2}$. Rendahnya nilai MOR diduga karena pengaruh ukuran serat penyusun papan partikel pada penelitian ini.

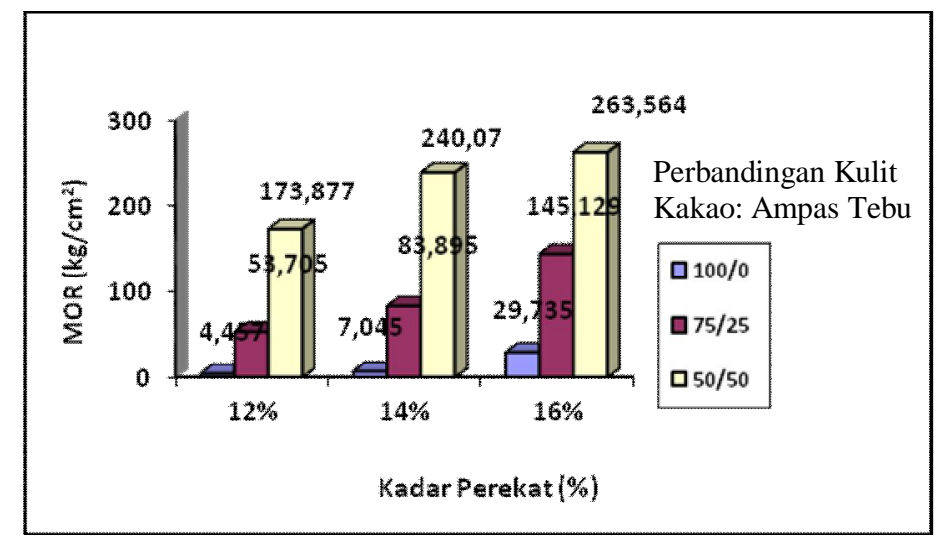

Gambar 4 Pengaruh Pengaruh Komposisi Kulit Buah Kakao, Ampas Tebu, dan Perekat terhadap Nilai MOR Papan Partikel

\subsection{Kuat Tekan Sejajar Permukaan (KTSP)}

Pengujian kuat tekan dilakukan dengan menggunakan UTM (Universal Testing Machine) uji kuat tekan digunakan untuk mengetahui kuat tekan hancur sampel uji. Dari Gambar 5 dapat dilihat bahwa nilai KTSP yang dihasilkan berkisar antara 4,358 kg/ $\mathrm{cm}^{2}-38,874$ $\mathrm{kg} / \mathrm{cm}^{2}$. Papan partikel dengan komposisi kulit buah kakao: ampas tebu 100:0 \% dengan kadar perekat $12 \%$ memeiliki nilai KTSP terendah, sedangkan nilai KTSP tertinggi diperoleh dari papan partikel dengan komposisi kulit buah kakao: ampas tebu 50:50 \% dengan kadar perekat $16 \%$. Dari diagram pada Gambar 5 dapat dilihat bahwa secara signifikan nilai KTSP meningkat dengan pertambahan jumlah kadar perekat. Hasil penelitian juga menunjukkan bahwa semakin banyak jumlah serat ampas tebu maka nilai KTSP semakin tinggi. Selain itu nilai KTSP juga dipengaruhi oleh kadar air dan kerapatan papan partikel yang dihasilkan. Nilai KTSP dari papan partikel yang diperoleh tidak jauh berbeda dengan penelitian Muryati (2017) tentang perbedaan persentase ampas pengolahan gambir dan serat tandan kosong kelapa sawit terhadap sifat papan partikel tanpa perekat yang menghasilkan nilai KTSP berkisar antara 21,68 $\mathrm{kg} / \mathrm{cm}^{2}$ sampai $47,34 \mathrm{~kg} / \mathrm{cm}^{2}$. Hal yang sama juga dilakukan oleh Ferdana (2016) tentang pengaruh perbedaan konsentrasi asam klorida pada pembuatan papan partikel tanpa perekat dari tongkol jagung menghasilkan nilai keteguhan tekan sejajar permukaan yang didapatkan pada pengujian papan partikel tanpa perekat berkisar antara 18,09-29,12 kg/ $\mathrm{cm}^{2}$. SNI 03-2105-2006, JIS A 5908 (2003) dan FAO (1996) tidak mensyaratkan nilai keteguhan tekan sejajar permukaan papan partikel. 


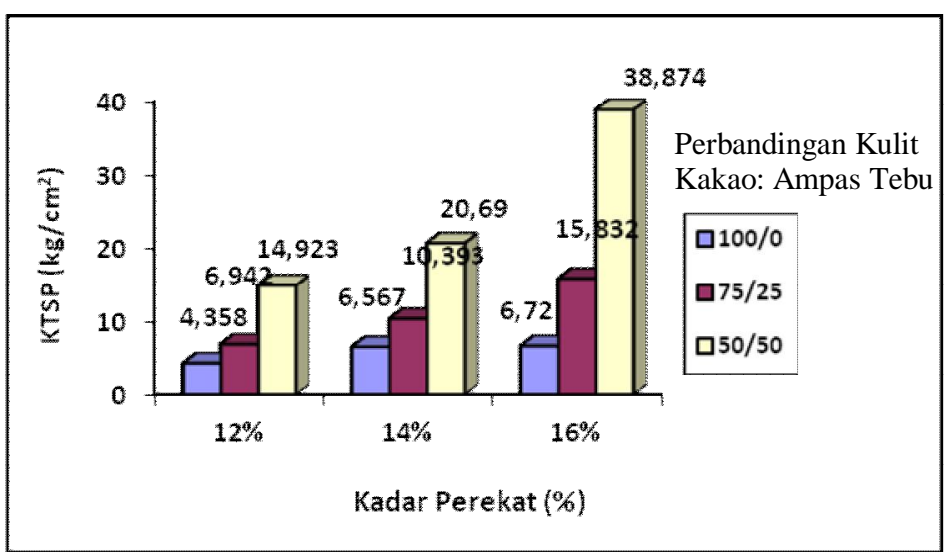

Gambar 5 Pengaruh Komposisi Kulit Buah Kakao, Ampas Tebu, dan Perekat terhadap Nilai KTSP Papan Partikel

\subsection{Kuat Rekat (IB = internal bonding)}

Keteguhan Rekat Internal diperoleh dengan cara merekatkan kedua permukaan contoh uji papan dengan menggunakan perekat epoxy pada balok besi kemudian balok besi tersebut ditarik secara berlawanan. Pada Gambar 6 dapat dilihat bahwa nilai IB yang didapatkan pada pengujian papan partikel berkisar antara $1,984 \mathrm{~kg} / \mathrm{cm}^{2}-10,096 \mathrm{~kg} / \mathrm{cm}^{2}$. Nilai IB tertinggi dihasilkan dari papan partikel dengan komposisi kulit buah kakao: ampas tebu 50:50 \% dengan kadar perekat $16 \%$. Sedangkan nilai IB terendah dihasilkan oleh papan partikel dengan komposisi kulit buah kakao: ampas tebu 100:0 \% atau tanpa serat dengan kadar perekat $12 \%$. Sesuai dengan penelitian Iskandar dan Supriadi (2013) yang menghasilkan nilai IB papan partikel ampas tebu tertinggi sebesar $2,33 \mathrm{~kg} / \mathrm{cm}^{2}$ dengan kadar perekat UF $10 \%$. Semakin tinggi kadar perekat yang digunakan, maka nilai IB yang dihasilkan juga akan semakin tinggi (Marpaung, 2015). Selain itu Maloney (1993) menyatakan bahwa nilai IB juga dipengaruhi oleh kadar air lembaran papan partikel. Gambar 6 juga menunjukkan bahwa semakin banyak serat maka nilai IB semakin tinggi. Hasil pengujian menunjukkan bahwa nilai IB yang dihasilkan telah sesuai dengan standar JIS A 5908 (2003) dan SNI 03-2105-2006 yang mensyaratkan minimal $1,5 \mathrm{~kg} / \mathrm{cm}^{2}$. Sedangkan untuk standar FAO (1996) tidak mensyaratkan pengujian nilai IB.

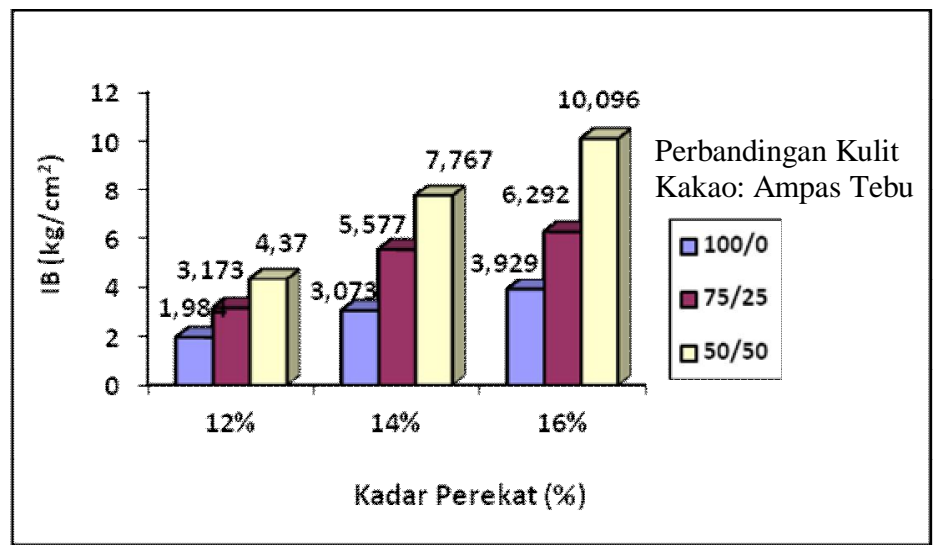

Gambar 6 Pengaruh Komposisi Kulit Buah Kakao, Ampas Tebu, dan Perekat terhadap Nilai IB Papan Partikel

\section{KESIMPULAN}

Berdasarkan penelitian yang telah dilakukan dapat diambil kesimpulan bahwa hasil penelitian menunjukkan adanya pengaruh variasi komposisi bahan dan jumlah perekat terhadap sifat fisis dan mekanis papan partikel. Papan partikel terbaik adalah papan partikel dengan perbandingan komposisi kulit buah kakao: 50:50\% dengan kadar perekat 16\%. Hasil penelitian menunjukkan bahwa nilai sifat fisis yang dihasilkan memenuhi standar JIS A 5908 (2003), SNI 03-2105-2006, dan FAO (1996). Namun pada pengujian nilai MOR terdapat beberapa papan 
yang tidak memenuhi standar. Berdasarkan persentase densitas papan partikel maka papan partikel yang dihasilkan termasuk jenis medium density particle board yang dapat digunakan untuk dbagian atas meja, lemari, tempat tidur dan lain-lain, serta high density particle board yang dapat digunakan untuk pembuatan dinding pemisah, pintu dan lain-lain.

\section{DAFTAR PUSTAKA}

Iskandar, MI., dan A. Supriadi, 2013, Pengaruh Kadar Perekat Terhadap Sifat Papan Partikel Ampas Tebu, Jurnal Penelitian Hasil Hutan, Vol.31.

Ferdana, F., 2016, Pengaruh Perbedaan Konsentrasi Asam Klorida Pada Pembuatan Papan Partikel Tanpa Perekat Dari Tongkol Jagung Terhadap Sifat Fisis Dan Mekanis Papan, Skripsi, Jurusan Teknologi Hasil Pertanian, Universitas Andalas, Padang.

Figueira A, Janick J \& Bemiller Jn, 1993, New Products from Theobroma Cacao: Seed Pulp And Pod Gum. New Crops (Janick J \& Simon Je, Eds), Pp. 475-478. Wiley, Ny.

Maiwita, F dkk., 2014, Pengaruh Komposisi Ampas tebu dan Serbuk Gergaji pada Papan Partikel terhadap Konduktivitas Termal, Pillar of Physics, Vol. 1, hal. 41-48.

Malau, J.C., Sucipto T., dan Iswanto A.H., 2015, Kualitas Papan Partikel Batang Pisang Barangan Berdasarkan Variasi Kadar Perekat Phenol Formaldehida (Particle Board Quality from Barangan Banana Stem Variation Based on Phenol Formaldehyde Resin Levels), Peronema Forestry Science Journal, Vol. 5, No. 1.

Maloney, TM., 1993, Modern Particleboard and Dry-Process Fiberboard Manufacturing, San Fransisco: Miller Freeman, Inc Rowell RM, 1988, The State of Art and the Future Development of Bio-based Composite Science and Technology Toward the 21st Century, Proceeding of the Fourth Pasific Bio-based Composites Symposium, Bogor.

Marpaung, Chamvion IR, dkk, Sifat Fisis dan Mekanis Papan Partikel Dari Serbuk Limbah Gergajian dengan Berbagai Kadar Perekat Isosianat (Physical and Mechanical properties of The Waste Sawdust Particle Board with Various of Isocyanate Adhesive levels), Peronema Forestry Science Journal, Vol. 4, No. 1.

Muryati, S., 2017, Pengaruh Perbedaan Persentase Ampas Pengolahan Gambir Dan Serat Tandan Kosong Kelapa Sawit Terhadap Sifat Papan Partikel Tanpa Perekat, Skripsi, Jurusan Teknologi Hasil Pertanian, Universitas Andalas, Padang.

Sulastiningsih IM, Novitasari, dan Turoso A., 2009, Pengaruh Kadar Perekat Terhadap Sifat Papan Partikel Bambu, Bogor, Jurnal Penelitian Hasil Hutan, hal. 13-14.

Sucipto, T., AH, Iswanto., dan Azhar, 2010, Karakteristik Papan Partikel dari Limbah Batang Sawit dengan Menggunakan Tiga Jenis Perekat, Jurnal Ilmu dan Teknologi Hasil Hutan, Vol. 3. 